Präv Gesundheitsf 2022 $17: 343$

https://doi.org/10.1007/s11553-021-00894-1

Online publiziert: 12. August 2021

(c) Der/die Autor(en) 2021

Denise Angélique Camenisch ${ }^{1}$ (D) · Olaf Schäfer ${ }^{2}$ Isabelle Andrea Minder ${ }^{1} \cdot$ Katja Cattapan ${ }^{3,4}$

${ }^{1}$ Health \& Medical Service AG, Zürich, Schweiz

${ }^{2}$ Service- und Leistungsmanagement, Helsana Gruppe, Dübendorf, Schweiz

${ }^{3}$ Psychotherapie und Privatstationen, Sanatorium Kilchberg AG, Kilchberg, Schweiz

${ }^{4}$ Universitätsklinik für Psychiatrie und Psychotherapie Bern, Bern, Schweiz

\title{
Erratum zu: Der Einfluss der Arbeit auf das Wohlbefinden unter Berücksichtigung verschiedener Berufsprofile
}

\section{Erratum zu:}

Präv Gesundheitsf 2021

https://doi.org/10.1007/s11553-021-

00875-4

In der ursprünglichen Version hatte leider die zweite Affiliation der Letztautorin Prof. Dr. Katja Cattapan, die Universitätsklinik für Psychiatrie und Psychotherapie Bern, gefehlt.

Der Originalbeitrag wurde korrigiert.

\section{Korrespondenzadresse}

\section{Denise Angélique Camenisch}

Health \& Medical Service AG

Löwenstrasse 59, 8001 Zürich, Schweiz

denise.camenisch@hmsag.ch

Open Access. Dieser Artikel wird unter der Creative Commons Namensnennung 4.0 International Lizenz veröffentlicht, welche die Nutzung, Vervielfältigung, Bearbeitung, Verbreitung und Wiedergabe in jeglichem Medium und Format erlaubt, sofern Sie den/die ursprünglichen Autor(en) und die Quelle ordnungsgemäß nennen, einen Link zur Creative Commons Lizenz beifügen und angeben, ob Änderungen vorgenommen wurden.

Die in diesem Artikel enthaltenen Bilder und sonstiges Drittmaterial unterliegen ebenfalls der genannten Creative Commons Lizenz, sofern sich aus der Abbildungslegende nichts anderes ergibt. Sofern das betreffende Material nicht unter der genannten Creative Commons Lizenz steht und die betreffende Handlung nicht nach gesetzlichen Vorschriften erlaubt ist, ist für die oben aufgeführten Weiterverwendungen des Materials die Einwilligung des jeweiligen Rechteinhabers einzuholen.
Weitere Details zur Lizenz entnehmen Sie bitte der Lizenzinformation auf http://creativecommons.org/ licenses/by/4.0/deed.de. 